\title{
Porous system analysis in artificial rock using X-ray tomographic image segmentation
} and numerical simulation.

Thiago Noboru Leite Kiam*, Alessandra Camilli Meletani, Milton Morais Xavier Júnior, Departamento de Geofísica, UFRN

Copyright 2021, SBGf - Sociedade Brasileira de Geofísica.

This paper was prepared for presentation during the $17^{\text {th }}$ International Congress of the Brazilian Geophysical Society held in Rio de Janeiro, Brazil, 8-11 November 2021 .

Contents of this paper were reviewed by the Technical Committee of the $17^{\text {th }}$ International Congress of the Brazilian Geophysical Society and do not necessarily represent any position of the SBGf, its officers or members. Electronic reproduction or storage of any part of this paper for commercial purposes without the written consent of the Brazilian Geophysical Society is prohibited.

\begin{abstract}
Natural resource reservoirs usually present a high degree of morphological heterogeneity. The risk of destructive processes during laboratory analysis, as well as the logistical and financial difficulty in obtaining and replacing reservoir samples, has led the scientific community to invest in less invasive and more cost-effective techniques. Thus, to overcome these challenges, computational petrophysics emerges as an approach for digital analysis and simulation of physical properties in porous systems to estimate parameters and preserve the integrity of analyzed samples. The purpose of this work is to simulate the fluid flow in a laminar regime on na artificial rock and to estimate porosity and permeability from X-ray microtomography images of the sample. The work started by using the Simpleware software for segmenting the X-ray image sequence of a cylindrical sample constituted by the sintering of glass spheres, with a voxel resolution of $0.019751 \mathrm{~mm}$. Aiming to reduce computation time, the sample was cut in the shape of a parallelepiped with dimensions of $13.8257 \times 13.8257 \times 0.217261 \mathrm{~mm}^{3}$. A threshold value was adopted following the Otsu method in order to distinguish pores from the grain phase. The mesh was elaborated in coarse size, containing a total of 27482 nodes. Then, the file was imported into Comsol Multiphysics software, which uses the Finite Element Method (FEM) to perform numerical simulations. The single-phase fluid utilized has characteristics similar to water, with density and dynamic viscosity respectively equal to $1000 \mathrm{~kg} / \mathrm{m}^{3}$ and $0.001 \mathrm{~Pa}$.s. A difference of $0.005 \mathrm{~Pa}$ in fluid pressure was applied to the model and the absolute porosity and permeability values reached $9.67 \%$ and $8.16 \times 10^{-10} \mathrm{~m}^{2}$, respectively. These results demonstrate that the employed technique is satisfactory and shows promise for use in the development of future work applied to natural rocks, given that digitally obtained parameters are compatible with laboratory petrophysical measurements.
\end{abstract}

Keywords: Computational petrophysics. Segmentation. Numerical Simulation. Petrophysics. Porosity. Permeability. 